\title{
Evolution of Photoluminescent CdS Magic-Size Clusters Assisted by Adding Small Molecules with Carboxylic Group
}

Zhengtian $\mathrm{He},{ }^{\dagger}$ Dongqing Wang, ${ }^{\dagger}$ Qiyu $\mathrm{Yu},{ }^{\prime \prime}, \perp$ Meng Zhang, ${ }^{\ddagger}$ Shanling Wang, ${ }^{\S}$ Wen Huang, ${ }^{\#}$ Chaoran Luan, ${ }^{*, \#}$ and Kui Yu*,+,,,

${ }^{\dagger}$ Engineering Research Center in Biomaterials, Sichuan University, Chengdu, Sichuan 610065, P. R. China

"College of Materials Science and Engineering, Sichuan University of Science and Engineering, Zigong, Sichuan 643000, P. R. China

${ }^{\ddagger}$ Institute of Atomic and Molecular Physics, Sichuan University, Chengdu, Sichuan 610065, P. R. China

${ }^{\S}$ Analytical \& Testing Center, Sichuan University, Chengdu, Sichuan 610065, P. R. China

\#Laboratory of Ethnopharmacology, West China School of Medicine, Sichuan University, Chengdu, Sichuan 610065, P. R. China

${ }^{\perp}$ State Key Laboratory of Polymer Materials Engineering, Chengdu, Sichuan 610065, P. R. China

*Correspondence and requests for materials should be addressed to

C. L. (email: luanchaoran@qq.com) or K. Y. (email: kuiyu@scu.edu.cn) 
Table of Contents

Figure S1 Temporal evolution of CdS MSC-373 at $180^{\circ} \mathrm{C} \quad \mathrm{S} 3$

Figure S2 Additional PLE spectra of MSC-373 S4

Figure S3 Temporal evolution of CdS MSC-373 from 140 to $240{ }^{\circ} \mathrm{C} \quad$ S5

Figure S4 Optical absorption of $\mathrm{CH}$ and Tol solvents $\quad \mathrm{S6}$

Figure S5 TEM images of purified MSC-373 with the scale bar of $50 \mathrm{~nm} \quad$ S7

$\begin{array}{lll}\text { Figure S6 FTIR study of purified MSC-373 S8 } & \text { S }\end{array}$

Table S1 EDS analysis of purified MSC-373 S9

$\begin{array}{lll}\text { Figure S7 XPS analysis of purified MSC-373 S10 } & \text { S }\end{array}$

$\begin{array}{lll}\text { Figure S8 XRD of purified MSC-373 S11 } & \text { X }\end{array}$

$\begin{array}{lll}\text { Table S2 Size calculation of purified MSC-373 S12 } & \text { S2 }\end{array}$

Figure S9 Evolution of absorption with the addition of C2, C4, and C6 acid S13

Figure S10 Optical absorption and emission with the addition of $\mathrm{Zn}(\mathrm{OAc})_{2}$ and $\mathrm{Mn}(\mathrm{OAc})_{2} \quad \mathrm{~S} 14$

Figure S11 Evolution of absorption with the Cd precursors of $\mathrm{Cd}(\mathrm{SA})_{2}$ and $\mathrm{Cd}(\mathrm{MA})_{2} \quad \mathrm{~S} 15$

Figure S12 Evolution of absorption with the different feed molar ratios of $\mathrm{Cd}$ to S S16

Figure S13 Evolution of absorption with 0/2/3 equivalent of HOAc addition S17

Figure S14 Evolution of absorption with 8/10/16 equivalent of HOAc addition S18

$\begin{array}{lll}\text { Figure S15 Optical properties of MSC-406 } & \text { S19 }\end{array}$

$\begin{array}{ll}\text { References } & \text { S20 }\end{array}$ 

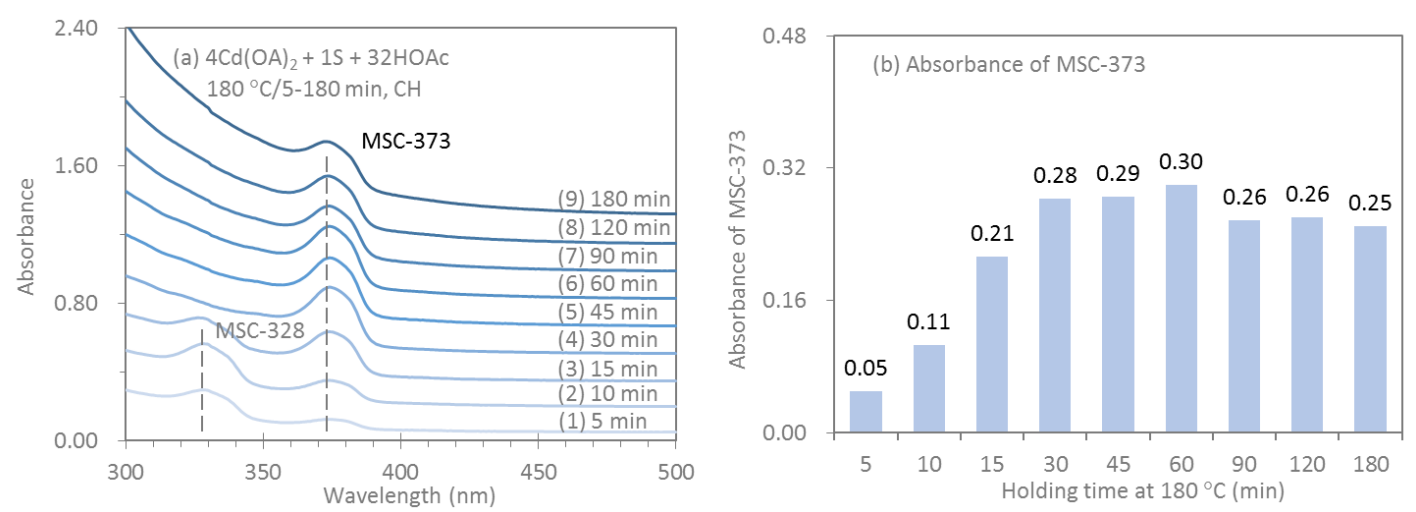

Figure S1. Temporal evolution of the optical absorption (a) with the constant temperature $\left(180^{\circ} \mathrm{C}\right)$ of $\mathrm{CdS}$ samples and the corresponding absorbance of CdS MSC373 at each holding time (b). The feed molar ratio of $\mathrm{Cd}(\mathrm{OA})_{2}(0.60 \mathrm{mmol})$ to $\mathrm{S}(0.15$ $\mathrm{mmol}$ ) was 4 to 1 with a $\mathrm{S}$ concentration of $30 \mathrm{mmol} / \mathrm{kg}$ in ODE, they were mixed at room temperature, and 32 equivalent of $\mathrm{HOAc}(4.80 \mathrm{mmol})$ was added under a $\mathrm{N}_{2}$ atmosphere at $120^{\circ} \mathrm{C}$. Then, the reaction temperature was increased and fixed at $180^{\circ} \mathrm{C}$ for 5-180 min, sampling was performed at (1) $5 \mathrm{~min}$, (2) $10 \mathrm{~min}$, (3) $15 \mathrm{~min}$, (4) $30 \mathrm{~min}$, (5) $45 \mathrm{~min},(6) 60 \mathrm{~min}$, (7) $90 \mathrm{~min}$, (8) $120 \mathrm{~min}$, and (9) $180 \mathrm{~min}$. The corresponding optical density (OD) value at each holding time was 0.05 (5 min), 0.11 (10 min), 0.21 (15 min), 0.28 (30 min), 0.29 (45 min), 0.30 (60 min), 0.26 (90 and 120 $\mathrm{min})$, and $0.25(180 \mathrm{~min}$ ) with the baseline absorbance at $388 \mathrm{~nm}$. A volume of $25 \mu \mathrm{L}$ of each sample was dispersed in $3.0 \mathrm{~mL}$ of $\mathrm{CH}$ for the optical study. It was clear that CdS MSC-373 was produced at $180^{\circ} \mathrm{C} / 5 \mathrm{~min}$. The amount of MSC-373 increased until $180^{\circ} \mathrm{C} / 60 \mathrm{~min}$ then decreased. 

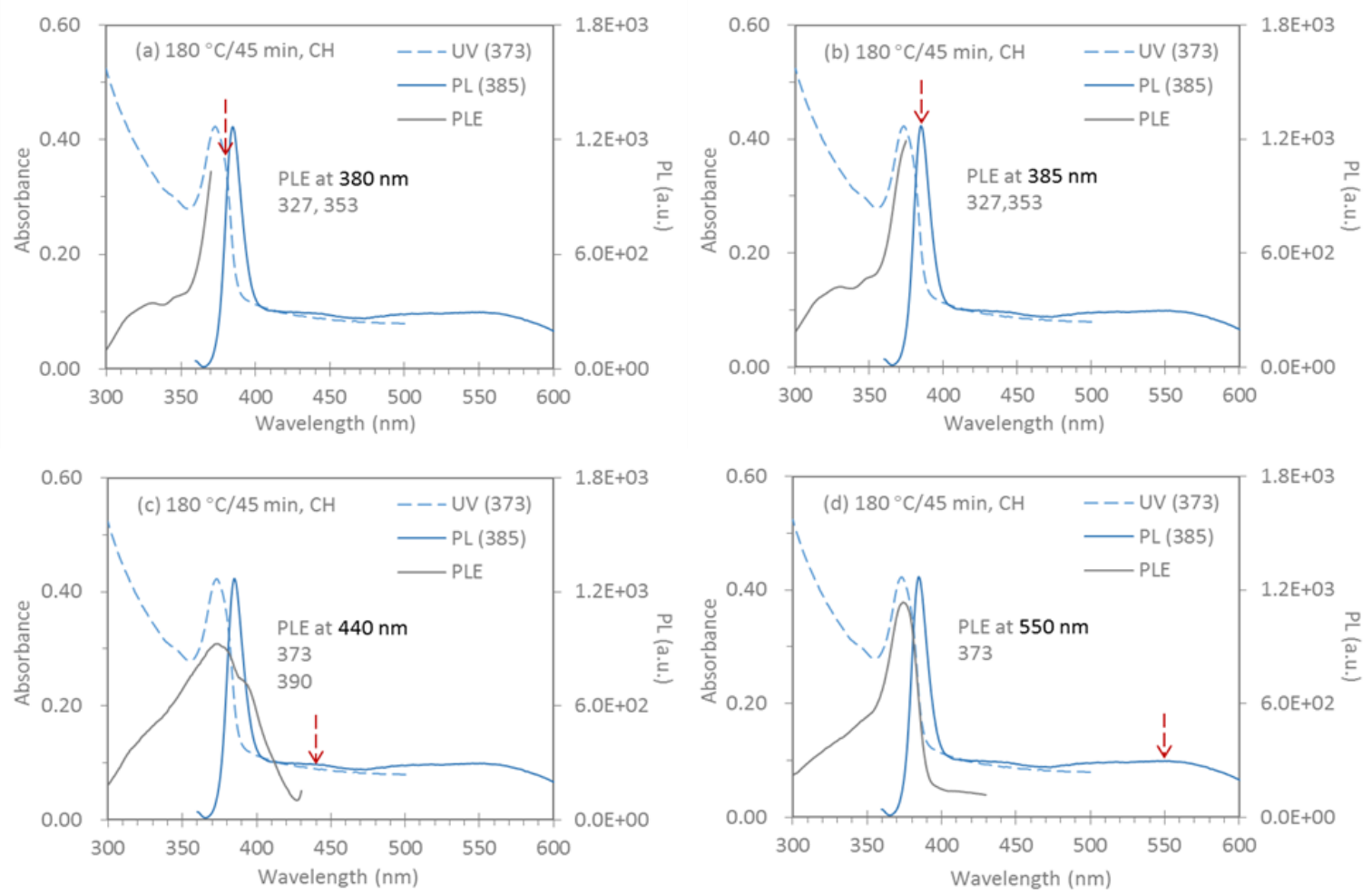

Figure S2. Normalized PLE (grey traces, with corresponding emission wavelengths indicated by dashed red arrows), optical absorption (dashed blue traces), and PL (blue traces excited at $350 \mathrm{~nm}$ ) spectra collected from sample $180^{\circ} \mathrm{C} / 45 \mathrm{~min}$ extracted from the batch presented in Figure S1. A volume of $25 \mu \mathrm{L}$ was dispersed in $3.0 \mathrm{~mL}$ of $\mathrm{CH}$ for the spectroscopy study. When the excitation wavelength was set at 380 (a) or (b) $385 \mathrm{~nm}$, the PLE spectrum had small peaks at 337 and $353 \mathrm{~nm}$. (c) When the excitation wavelength was set at $440 \mathrm{~nm}$, the PLE spectrum had peaks at 373 and $390 \mathrm{~nm}$. (d) When the excitation wavelength was moved at $550 \mathrm{~nm}$, the PLE spectrum had the lowest-energy peak at $373 \mathrm{~nm}$. It seems that CdS MSC-373 was the only emission source contributing to the PL peaking at $385 \mathrm{~nm}$. 

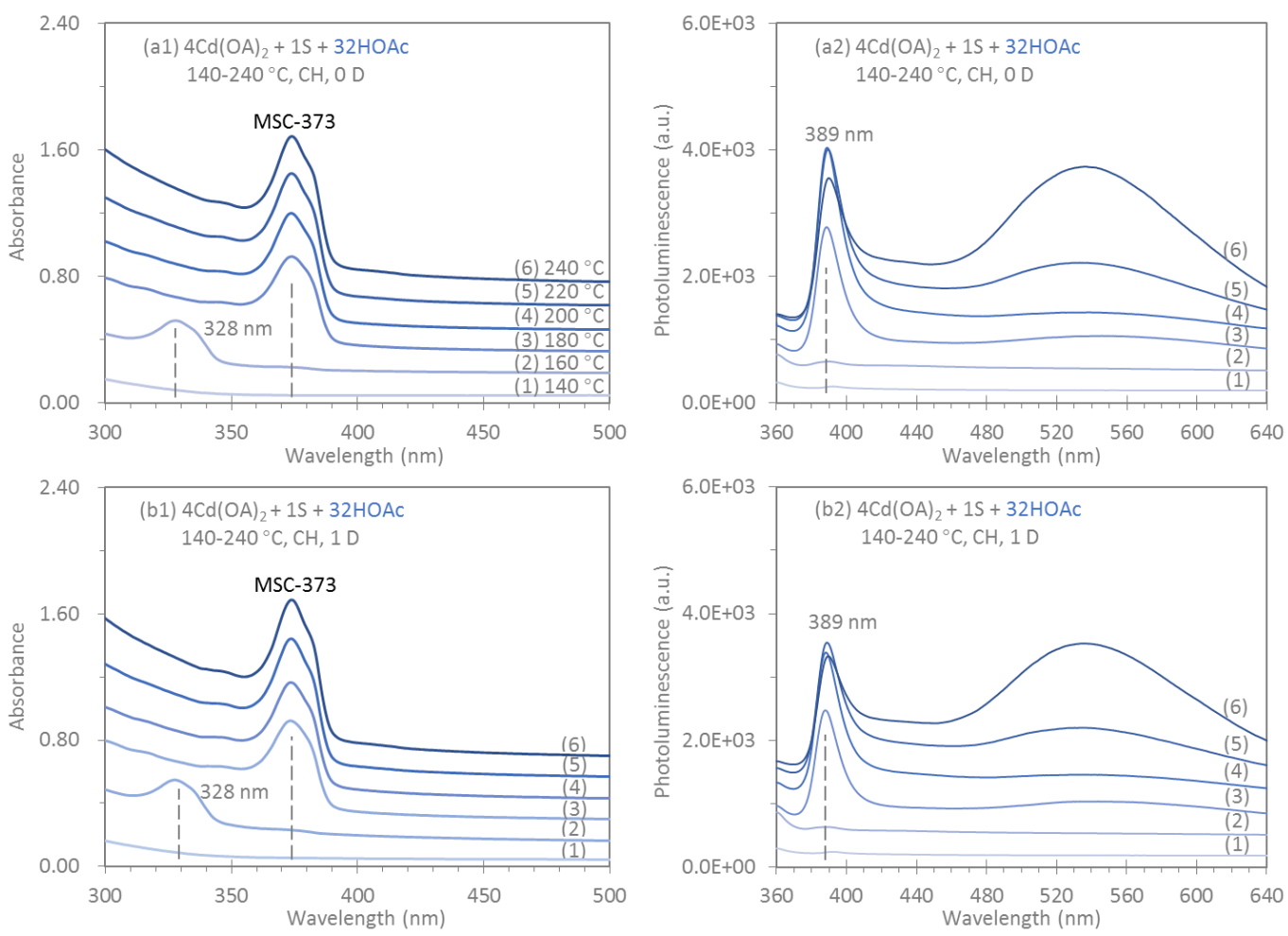

Figure S3. Evolution of optical absorption (a1 and b1, left) and emission ( $a 2$ and b2, right, excited at $350 \mathrm{~nm}$ ) with increasing temperature from 140 to $240{ }^{\circ} \mathrm{C}$ of $\mathrm{CdS}$ samples without (a1 and a2) and with one-day incubation (b1 and b2). The staring materials and addition were similar to the batch in Figure S1, samples were taken after the reaction was held for $15 \mathrm{~min}$ at (1) $140^{\circ} \mathrm{C}$, (2) $160^{\circ} \mathrm{C},(3) 180^{\circ} \mathrm{C}$, (4) $200^{\circ} \mathrm{C}$, (5) $220^{\circ} \mathrm{C}$, and (6) $240{ }^{\circ} \mathrm{C}$. Each sample $(25 \mu \mathrm{L})$ was dispersed in $3.0 \mathrm{~mL}$ of $\mathrm{CH}$ for the spectroscopy study. Obviously, CdS MSC-373 was produced during the temperature increase from 180 to $240{ }^{\circ} \mathrm{C}$ and changed little after one-day incubation, which implies that MSC-373 was quite stable. 

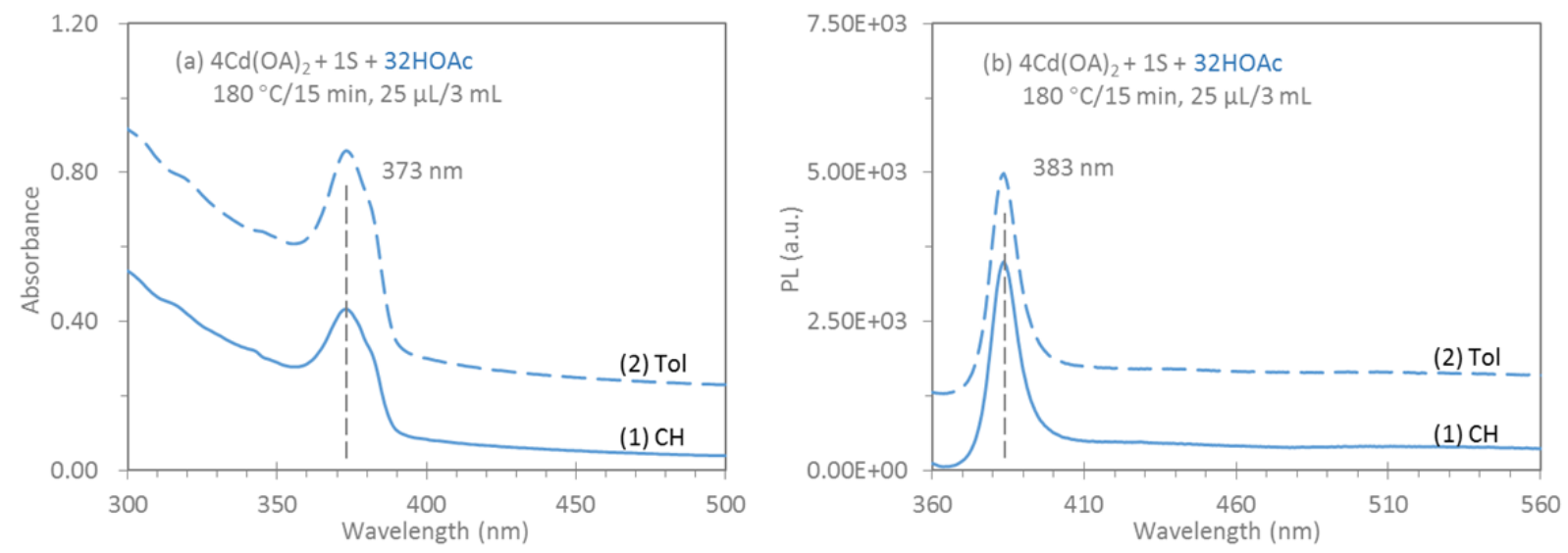

Figure S4. Optical absorption (a) and emission (b) spectra of one as-synthesized CdS sample $\left(180^{\circ} \mathrm{C} / 45 \mathrm{~min}, 25 \mu \mathrm{L}\right.$ in $3.0 \mathrm{~mL} \mathrm{CH}$ or Tol) from the batch in Figure $\mathrm{S} 1$. We found that both $\mathrm{CH}$ and Tol were suitable for the background measurements of $\mathrm{CdS}$ MSC-373. And the different OD values in dispersions were related to the different absorbance coefficients of the dispersions. 


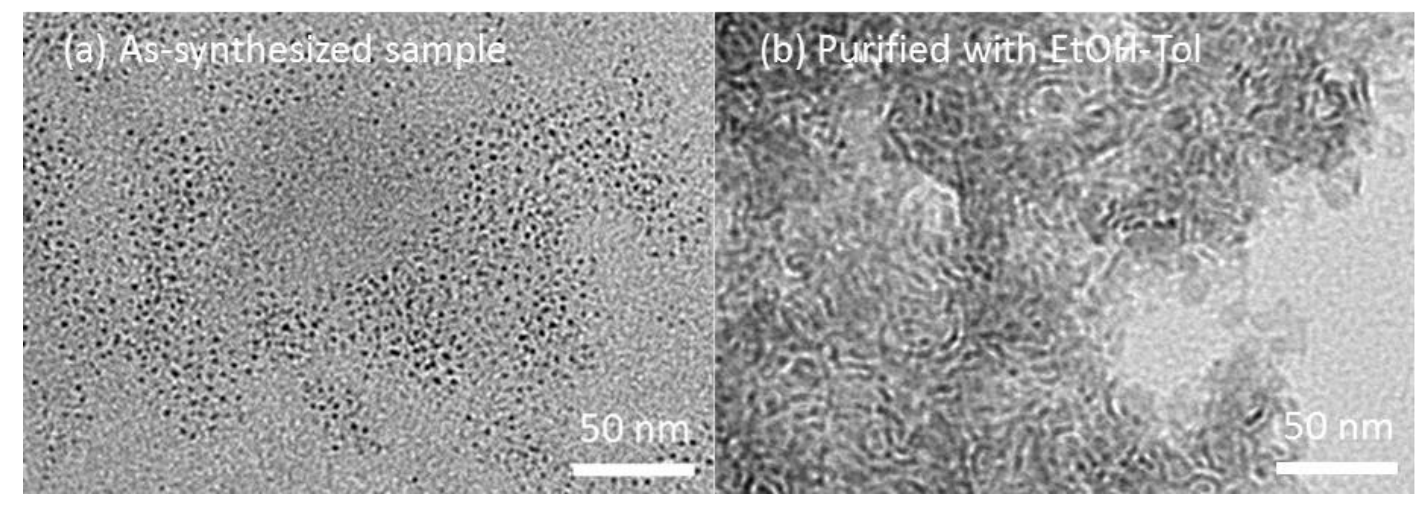

Figure S5. TEM images of the as-synthesized (a) and the purified CdS MSC-373 (b) extracted from the batch in Figure 2. The scale bars were $50 \mathrm{~nm}$. Obviously, the morphology of the as-synthesized CdS MSC-373 was dot-like, which was changed to be flake-like after the purification. 


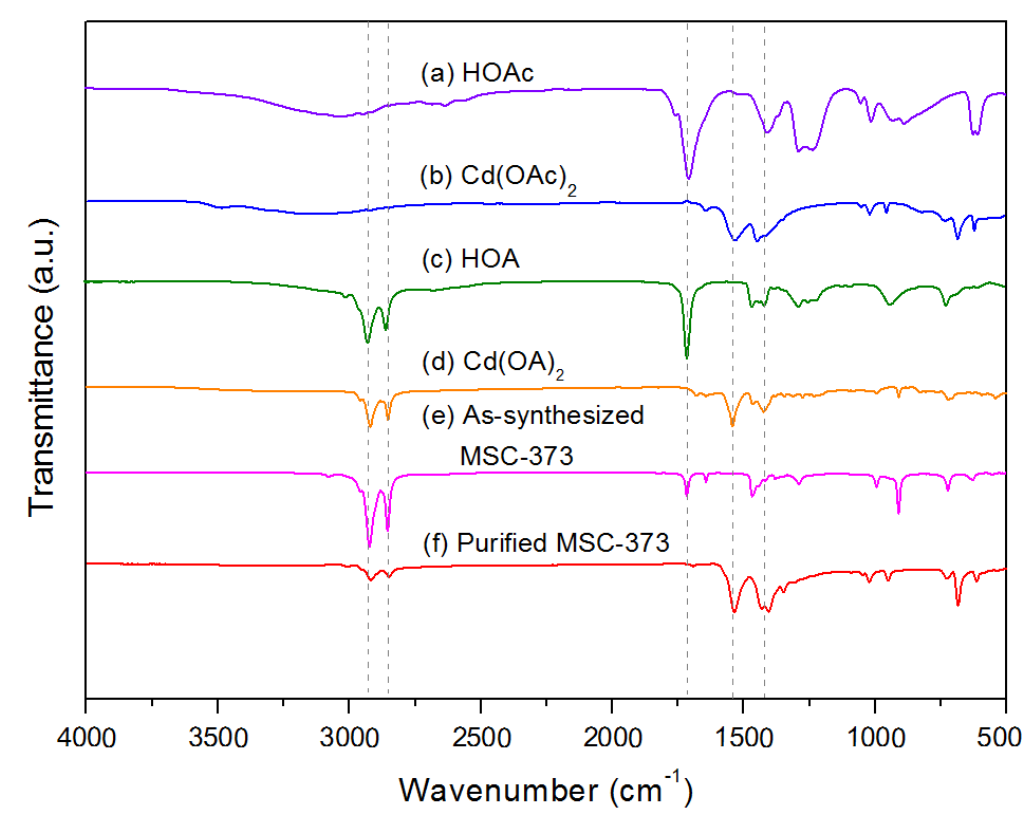

Figure S6. FTIR study of the ligand changes of MSC-373. The samples of HOAC (a), $\mathrm{Cd}(\mathrm{OAc})_{2}(\mathrm{~b})$, and $\mathrm{HOA}(\mathrm{c})$ were purchased; while the samples of $\mathrm{Cd}(\mathrm{OA})_{2}(\mathrm{~d})$, assynthesized MSC-373 (e), and purified MSC-373 (f) were prepared.

For HOAc (a) and HOA (c), fatty acids without complexing with $\mathrm{Cd}^{2+}$, the characteristic signal of $1712 \mathrm{~cm}^{-1}$ ( $\mathrm{C}=\mathrm{O}$ band) was observed. While for $\mathrm{Cd}(\mathrm{OAc})_{2}$ (b) and $\mathrm{Cd}(\mathrm{OA})_{2}(\mathrm{~d})$, the characteristic signal of acetate appeared at 1534 and $1425 \mathrm{~cm}^{-1}$ (C-O band). For samples (c) to (f), the characteristic signal of oleate groups (2923 and $2850 \mathrm{~cm}^{-1}$ for the $\mathrm{C}-\mathrm{H}$ bond of $-\mathrm{CH}_{2}$ ) has been observed. ${ }^{1}$ Comparing (e) and (f), after the purification, the signal at $1712 \mathrm{~cm}^{-1}$ disappeared, which implied that free HOAC (a) and HOA (c) have been removed. The signal at 2923 and $2850 \mathrm{~cm}^{-1}$ in (f) is weaker than that in (e), which implied that the HOA ligand has been stripped during purification. And comparing (d) and (f), we found that the intensity ratio of the signals at 2923 and $1534 \mathrm{~cm}^{-1}$ changed. We believe the results support our proposal of the ligand exchange process. 
Table S1. EDS analysis of the purified CdS MSC-373.

\begin{tabular}{|c|c|c|c|c|c|c|c|}
\hline & $\begin{array}{l}\text { Atomic } \\
\text { Conc. }\end{array}$ & $\begin{array}{l}\text { Weight } \\
\text { Conc. }\end{array}$ & $\begin{array}{l}\text { Atomic } \\
\text { Conc. }\end{array}$ & $\begin{array}{l}\text { Weight } \\
\text { Conc. }\end{array}$ & $\begin{array}{l}\text { Atomic } \\
\text { Conc. }\end{array}$ & $\begin{array}{l}\text { Weight } \\
\text { Conc. }\end{array}$ & Mean \\
\hline $\mathrm{Cd}$ & 11.31 & 50.69 & 12.32 & 52.84 & 3.24 & 22.58 & \\
\hline$S$ & 5.76 & 7.37 & 6.33 & 7.75 & 1.56 & 3.11 & \\
\hline C & 69.05 & 33.08 & 67.34 & 30.86 & 81.73 & 60.93 & \\
\hline \multirow[t]{2}{*}{ O } & 13.88 & 8.86 & 14.01 & 8.55 & 13.47 & 13.38 & \\
\hline & \multicolumn{2}{|c|}{ Area 1} & \multicolumn{2}{|c|}{ Area 2} & \multicolumn{2}{|c|}{ Area 3} & \\
\hline $\mathrm{Cd} / \mathrm{S}$ & 1.96 & & 1.95 & & 2.08 & & 2.00 \\
\hline $\mathrm{C} / \mathrm{O}$ & 4.97 & & 4.81 & & 6.07 & & 5.28 \\
\hline
\end{tabular}

The percentages of $C d, S, C$ and $O$ were determined and the sum was set to $100 \%$.

The elemental composition for three areas was summarized in the table above. The mean atom ratio of $C d$ to $S$ was about 2.00, and that of $C$ to $O$ was about 5.28. 

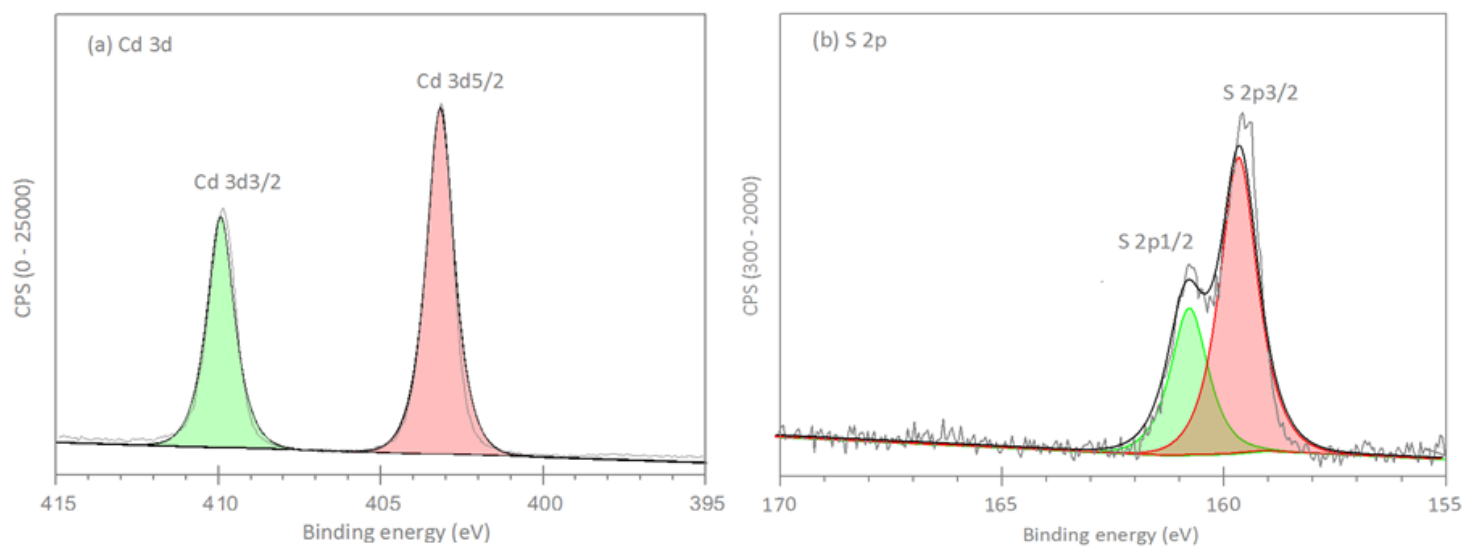

Figure S7. X-ray photoelectron spectroscopy analysis of the purified CdS MSC-373. (a) The expanded view in the range of 395 to $415 \mathrm{eV}$ of $\mathrm{Cd} 3 \mathrm{~d}$, fitted at $409.94 \mathrm{eV}$ of $\mathrm{Cd}$ 3d3/2 (green curve) and $403.19 \mathrm{eV}$ of $\mathrm{Cd} 3 \mathrm{~d} 5 / 2$ (pink curve). (b) The expanded view in the range of 155 to $170 \mathrm{eV}$ of S $2 \mathrm{p}$, fitted at $159.56 \mathrm{eV}$ of S 2p1/2 (green curve) and $160.78 \mathrm{eV}$ of S 2p3/2 (pink curve). The $\mathrm{Cd} / \mathrm{S}$ ratio was about 1.85 . 


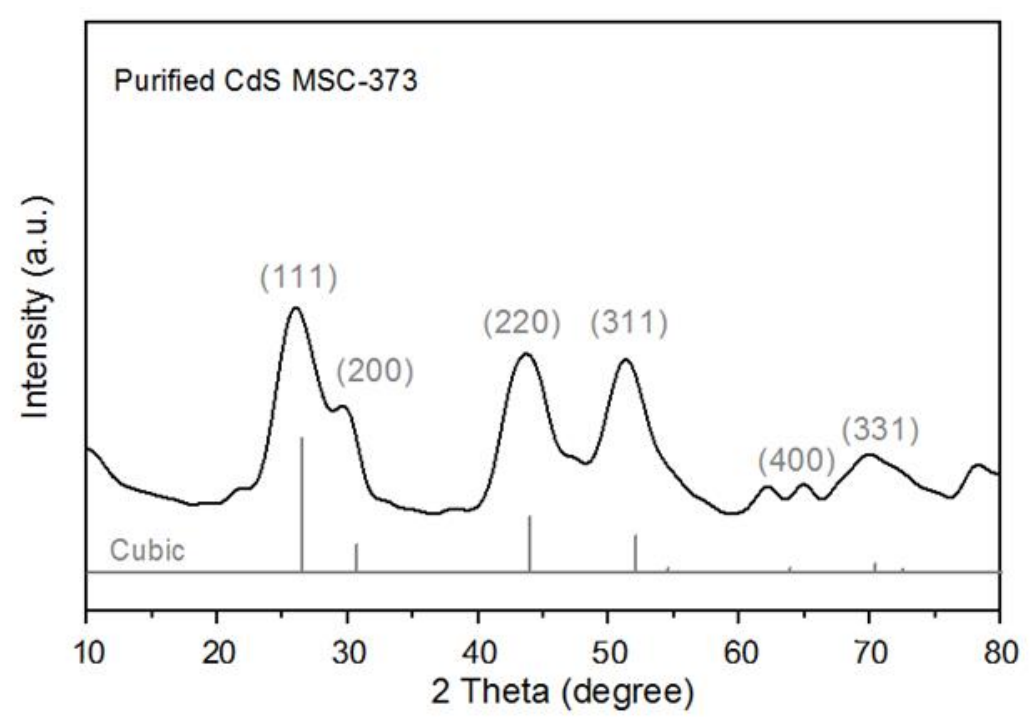

Figure S8. X-ray diffraction patterns of the purified CdS MSC-373 with $180^{\circ} \mathrm{C} / 45 \mathrm{~min}$ growth similar to the batch in Figure S1. The purification method was according to that of Figure S5. The standard diffraction peaks of CdS with the cubic structure (JCPDS card no. 89-0440) are inserted as grey lines in the bottom for reference. 
Table S2. The size calculation of purified MSC-373.

\begin{tabular}{lcccccc}
\hline & $2 \theta\left({ }^{\circ}\right)$ & $d_{h k l}(\AA)$ & Structure & $\mathrm{a}(\AA)$ & $B_{h k l}$ & $D_{h k l}(n m)$ \\
\hline Bulk CdS & $26.456(111)$ & 3.366 & Cubic & 5.830 & & \\
MSC-373 & $26.371(111)$ & 3.377 & Cubic-like & 5.849 & 0.071 & $1.943(220)$ \\
\hline
\end{tabular}

The Bragg angle $(\theta)$, interplanar spacing $\left(d_{h k l}\right)$, lattice parameters $(a)$, and the full width at half maximum of the $\mathrm{X}$-ray diffraction peak in radians $\left(\mathrm{B}_{\mathrm{hkl}}\right)$ were obtained based on the Bragg equation and MDI Jade 6 software, the size in the direction perpendicular to the lattice plane $\left(D_{h k l}\right)$ was calculated by the Scherrer equation..$^{2-4}$ According to Scherrer equation, the size of MSC-373 calculated is around $1.94 \mathrm{~nm}$, which is in agreement with the observation in TEM.

1. Bragg equation: $2 d_{h k \mid} \sin \theta=n \lambda$

2. Cubic lattice parameter $(a=b=c): d_{h k l}=\frac{a}{\sqrt{h^{2}+k^{2}+l^{2}}}$

3. Scherrer equation: $D_{h k l}=K \lambda /\left(B_{h k l} \cos \theta\right)$

$\mathrm{K}$ (a numerical factor referred to as the shape factor) $=0.89$.

$\lambda$ (the wavelength of the $X$-rays) $=0.1506 \mathrm{~nm}$. 

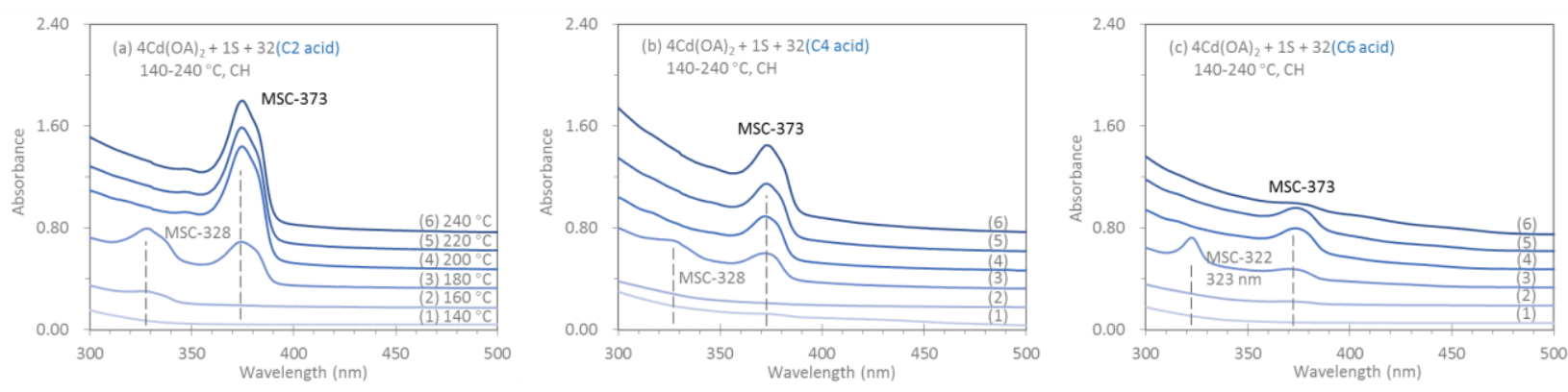

Figure S9. Evolution of optical absorption with increasing temperature from 140 to $240{ }^{\circ} \mathrm{C}$ of $\mathrm{CdS}$ samples with the addition of acetic acid (C2 acid, left, a), butyric acid ( $\mathrm{C} 4$ acid, middle, b), and hexanoic acid ( $\mathrm{C} 6$ acid, right, c). $\mathrm{Cd}(\mathrm{OA})_{2}(0.60 \mathrm{mmol}$ ) and $\mathrm{S}$

(0.15 mmol) were mixed in ODE with the feed moral ratio of 4 to 1 and a $S$ concentration of $30 \mathrm{mmol} / \mathrm{kg}$, when 32 equivalent of the acid $(4.80 \mathrm{mmol})$ was added at $120^{\circ} \mathrm{C}$ under a $\mathrm{N}_{2}$ atmosphere. Then, the reaction temperature was increased to $240{ }^{\circ} \mathrm{C}$ in steps of $20^{\circ} \mathrm{C}$, sampling was performed at (1) $140{ }^{\circ} \mathrm{C}$, (2) 160 ${ }^{\circ} \mathrm{C}$, (3) $180^{\circ} \mathrm{C}$, (4) $200^{\circ} \mathrm{C}$, (5)220 ${ }^{\circ} \mathrm{C}$, and (6) $240{ }^{\circ} \mathrm{C} / 15 \mathrm{~min}$. Each $(25 \mu \mathrm{L})$ of the samples was dispersed in $3.0 \mathrm{~mL}$ of $\mathrm{CH}$ for spectroscopy study. It seems that the short carbon length of the acids favors the formation of MSC-373. 

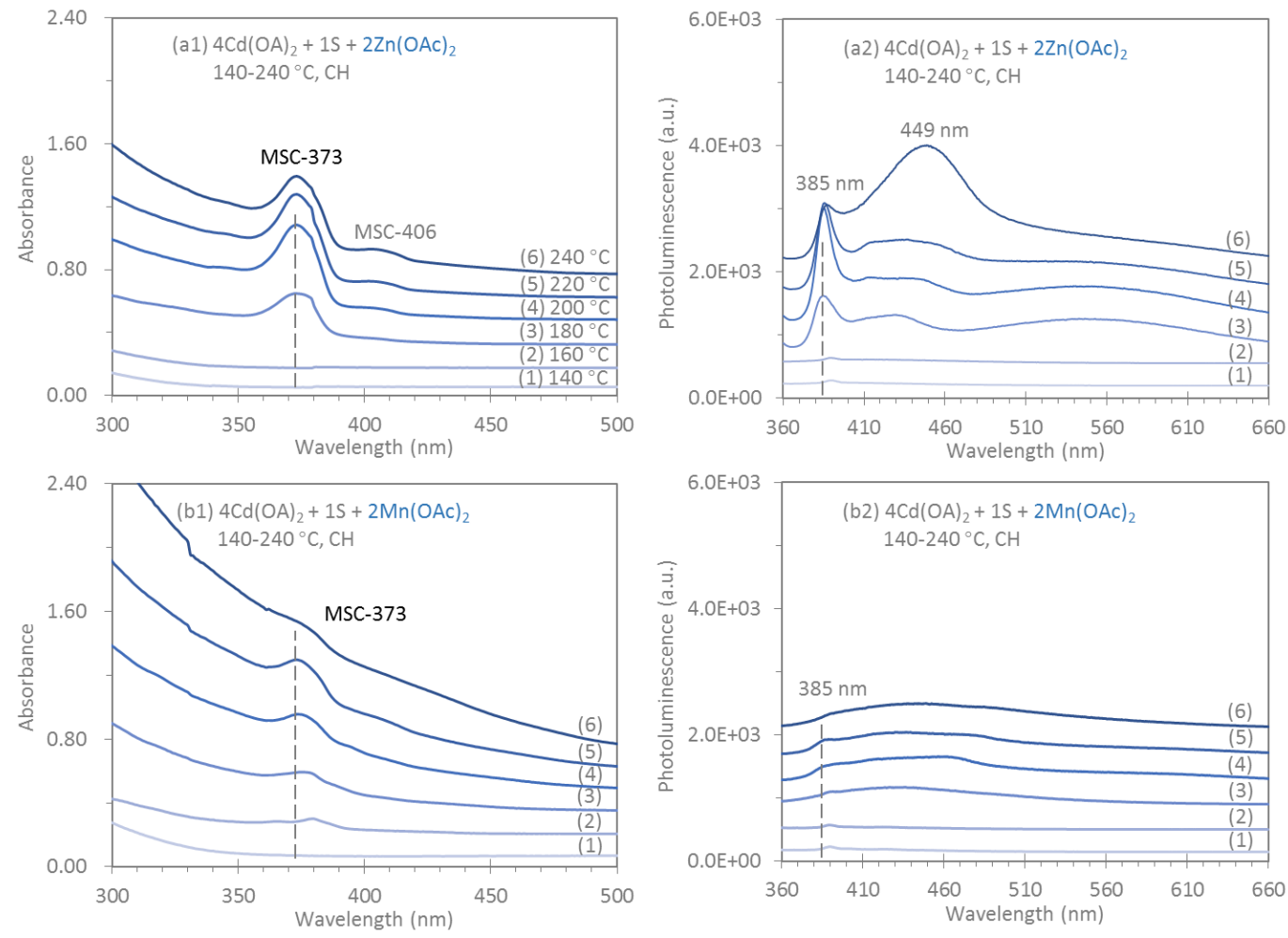

Figure S10. Evolution of optical absorption ( $a 1$ and b1, left) and photoluminescence (a2 and b2, right) with increasing temperature from 140 to $240{ }^{\circ} \mathrm{C}$ of $\mathrm{CdS}$ samples with the addition of $\mathrm{Zn}(\mathrm{OA})_{2}(\mathrm{a} 1$ and $\mathrm{a} 2)$ and $\mathrm{Mn}(\mathrm{OAc})_{2}(\mathrm{~b} 1$ and $\mathrm{b} 2$ ). Similar to Figure S9 batches, 2 equivalent of acetate $(0.30 \mathrm{mmol})$ was performed at $120^{\circ} \mathrm{C}$. Evidently, a larger amount of MSC-373 was produced with the addition of $\mathrm{Zn}(\mathrm{OA})_{2}$, compared to the addition of $\mathrm{Mn}(\mathrm{OA})_{2}$. According to the emission spectra, $\mathrm{Zn}$ or $\mathrm{Mn}$ atoms should not take part in the composition of MSC-373. 

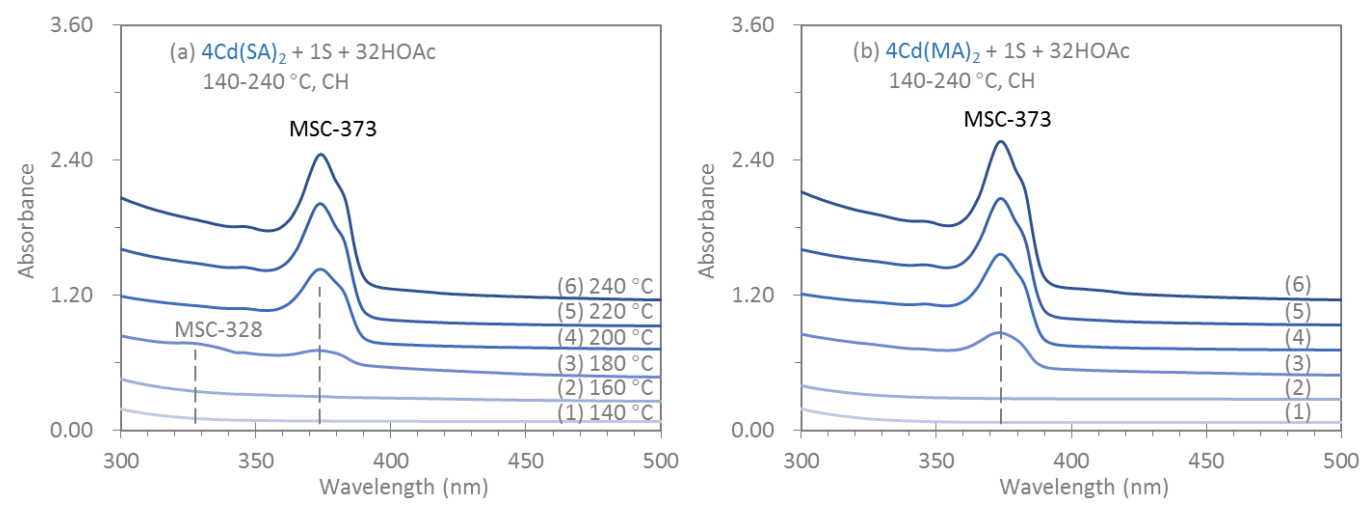

Figure S11. Evolution of optical absorption of the samples extracted from two CdS batches with $\mathrm{Cd}(\mathrm{SA})_{2}(\mathrm{a})$ and $\mathrm{Cd}(\mathrm{MA})_{2}(\mathrm{~b})$ as $\mathrm{Cd}$ precursors. MSC-373 was observed in both batches, while a tiny peak of MSC-328 was obtained at $180^{\circ} \mathrm{C}$ in batch a. It seems that the Cd precursor was not critical to form MSC-373. 

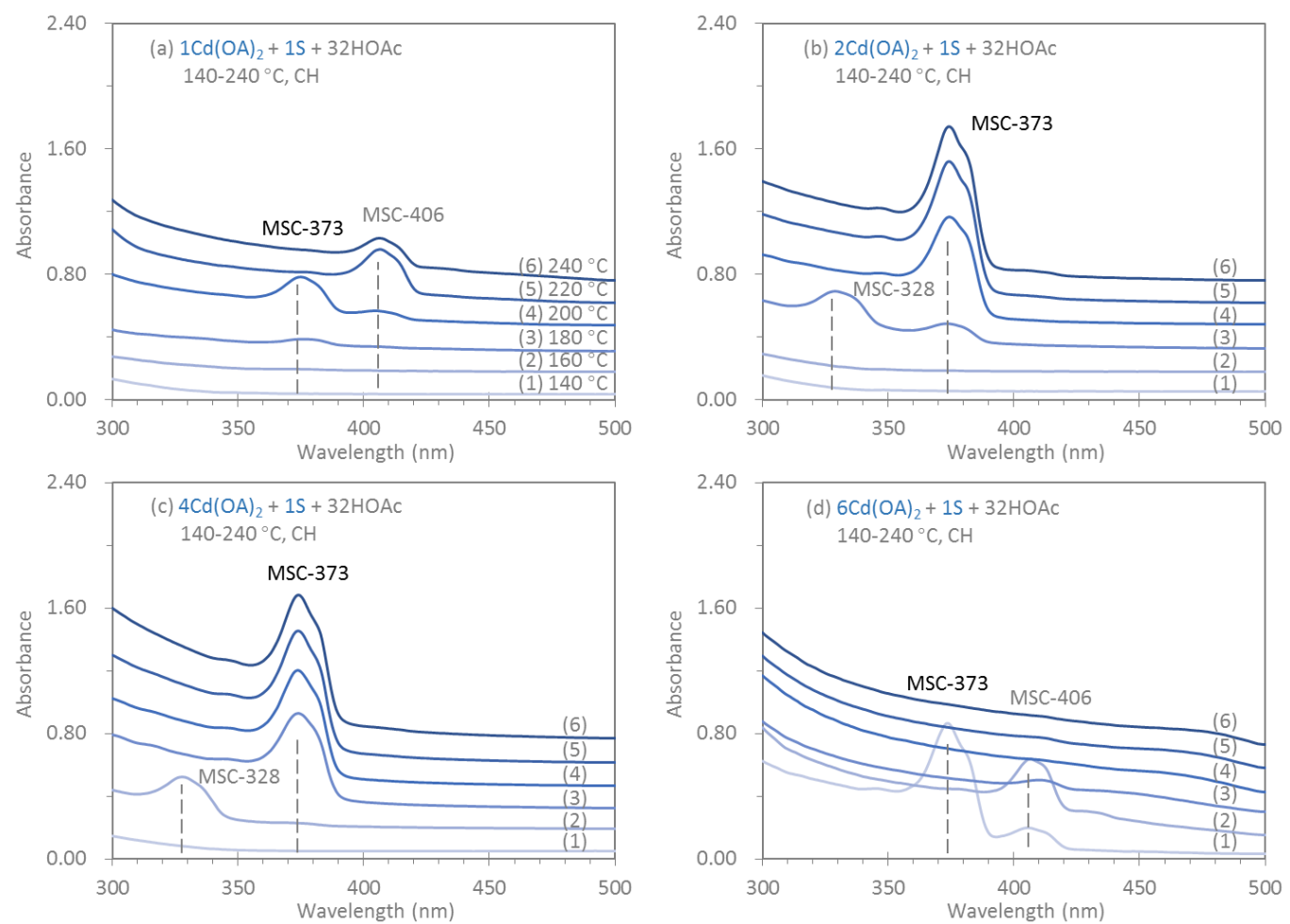

Figure S12. Evolution of optical absorption of the samples extracted from two CdS batches with Cd:S ratio of 1 (a), 2 (b), 4 (c), and 6 (d), in which 32 equivalent HOAc was used as additive. The yield of MSC-373 in batches $b$ and $c$ was larger than that in batches $\mathrm{a}$ and $\mathrm{d}$. It was worthy of notice that the temperature to form MSC-373 declined with the increase of the Cd:S ratio. 

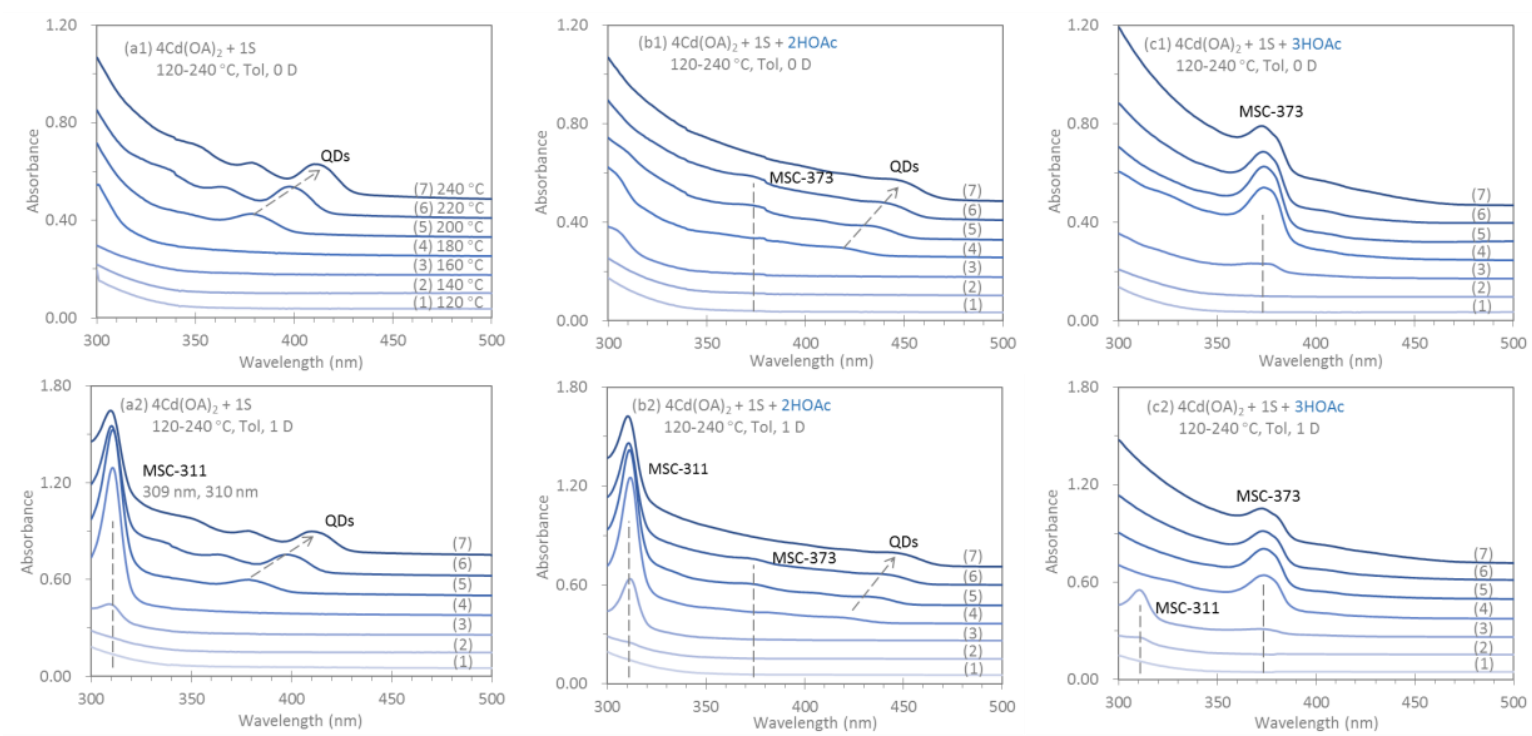

Figure S13. Evolution of optical absorption properties of CdS samples ( $25 \mu \mathrm{L}$ in 3.0

$\mathrm{mL}$ Tol) from three reaction batches with (a1 and a2) no HOAc addition, (b1 and b2) 2 equivalent of $\mathrm{HOAc}(0.30 \mathrm{mmol})$, and ( $\mathrm{c} 1$ and $\mathrm{c} 2) 3$ equivalent of $\mathrm{HOAc}(0.45 \mathrm{mmol})$. Absorption measurements were carried out immediately (in the top panel) and after one-day storage (in the bottom panel). The addition of HOAc for $b$ and $c$ was performed at $120^{\circ} \mathrm{C}$. Afterward, the reaction temperature was increased from 120 to $240{ }^{\circ} \mathrm{C}$ in steps of $20^{\circ} \mathrm{C}$. Samples were extracted at each temperature after $15 \mathrm{~min}$ had elapsed. It was clear that the addition of HOAc can promote the formation of MSC-373 and suppress the formation of MSC-311 and QDs. 

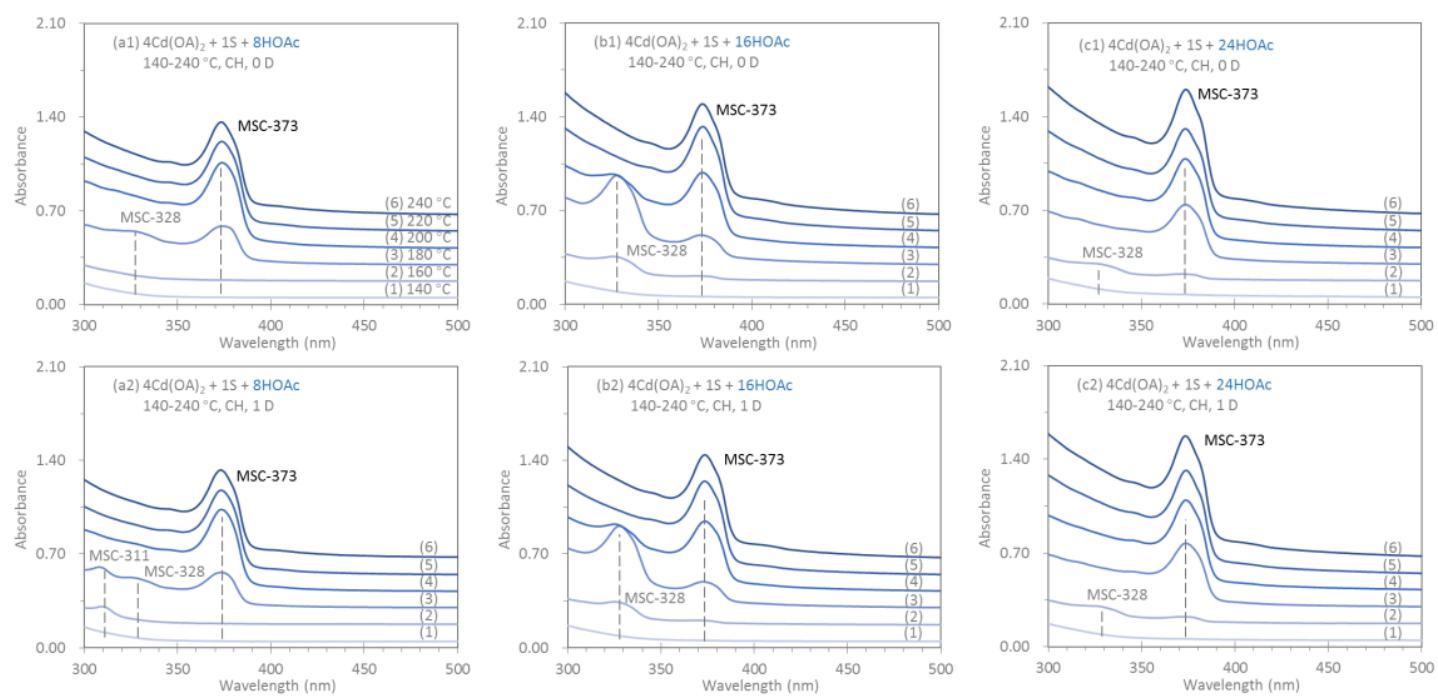

Figure S14. Evolution of optical absorption properties of CdS samples ( $25 \mu \mathrm{L}$ in 3.0

$\mathrm{mL} \mathrm{CH}$ ) from three reaction batches with (a1 and a2) 8 equivalent of HOAc (1.20 mmol), (b1 and b2) 16 equivalent of $\mathrm{HOAc}(2.40 \mathrm{mmol})$, and (c1 and c2) 24 equivalent of $\mathrm{HOAc}(3.60 \mathrm{mmol})$. Absorption measurements were carried out immediately (top panel) and after one-day storage (bottom panel). The addition and sampling were performed similar to that of Figure S11, batch a. In the range from 1.20 to $3.60 \mathrm{mmol}$, the larger amount of HOAc was added, the larger amount of MSC-373 was produced. 


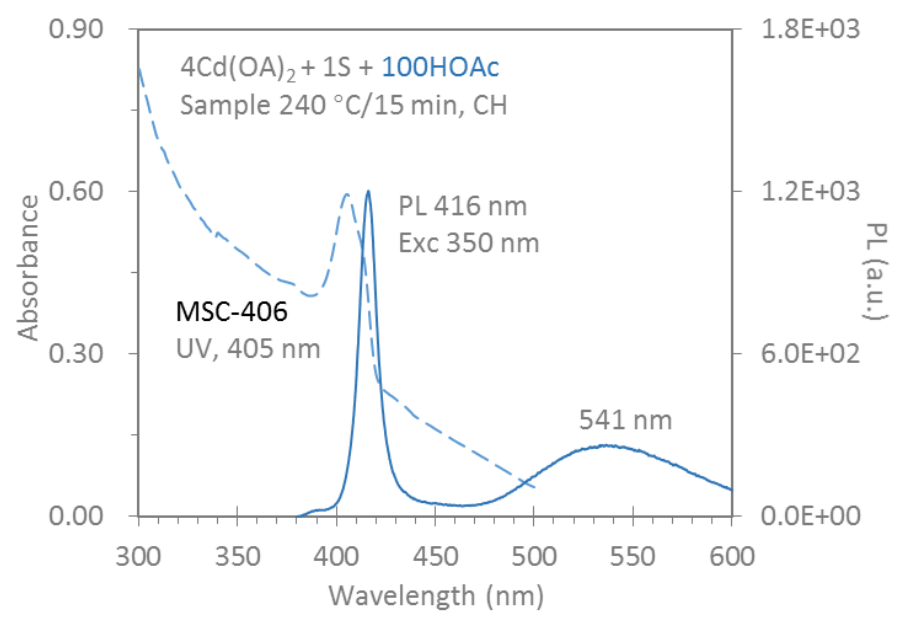

Figure S15. Optical absorption (dash blue trace) and photoemission (solid blue trace, excited at $350 \mathrm{~nm})$ of MSC-406 extracted from a reaction batch of $\mathrm{Cd}(\mathrm{OA})_{2}(0.60$ $\mathrm{mmol})$ and $\mathrm{S}(0.15 \mathrm{mmol})$ in ODE with a $\mathrm{S}$ concentration of $30 \mathrm{mmol} / \mathrm{kg}$. The addition of $\mathrm{HOAC}(15.00 \mathrm{mmol})$ was performed at $120^{\circ} \mathrm{C}$. Afterward, the reaction temperature was increased from 120 to $240^{\circ} \mathrm{C}$ in steps of $20^{\circ} \mathrm{C}$, with a holding time of $15 \mathrm{~min}$ at each temperature. The sample was taken at $240{ }^{\circ} \mathrm{C} / 15 \mathrm{~min}$. CdS MSC406 evolved with 15.00 mmol HOAc addition, which exhibits the band edge and trap emission peaks respectively at 416 and $541 \mathrm{~nm}$. 


\section{References}

(1) Nevers, D. R.; Williamson, C. B.; Hanrath, T.; Robinson, R. D. Surface Chemistry of Cadmium Sulfide Magic-Sized Clusters: A Window into Ligand-Nanoparticle Interactions. Chem. Commun. 2017, 53, 2866-2869.

(2) Bragg, W. H. The Reflection of X-Rays by Crystals. Nature 1913, 91, 447.

(3) Scherrer, P. Nachrichten von der Gesellschaft der Wissenschaften zu Göttingen; Weidmannsche Buchhandlung., Berlin, 1918.

(4) Holzwarth, U.; Gibson, N. The Scherrer Equation Versus the 'Debye-Scherrer Equation'. Nat. Nanotechnol. 2011, 6, 534. 